\title{
Reappraisal of mechanical tricuspid valve replacement in the current era: a single center retrospective study
}

\author{
Byungjoon Park ${ }^{1,2 \#}$, Dong Seop Jeong ${ }^{1 \#}$, Wook Sung Kim ${ }^{1} \wedge$, Kiick Sung ${ }^{1 \wedge}$, Pyo Won Park $^{1,3} \wedge$ \\ ${ }^{1}$ Department of Thoracic and Cardiovascular Surgery, Samsung Medical Center, Sungkyunkwan University School of Medicine, Seoul, Korea; \\ ${ }^{2}$ Department of Thoracic and Cardiovascular Surgery, Chung-Ang University Hospital, Chung-Ang University School of Medicine, Seoul, Korea; \\ ${ }^{3}$ Department of Thoracic and Cardiovascular Surgery, Mediplex Sejong Hospital, Incheon, Korea \\ Contributions: (I) Conception and design: PW Park, B Park; (II) Administrative support: PW Park, DS Jeong; (III) Provision of study materials or \\ patients: PW Park, B Park, DS Jeong; (IV) Collection and assembly of data: PW Park, B Park; (V) Data analysis and interpretation: B Park, PW \\ Park, DS Jeong; (VI) Manuscript writing: All authors; (VII) Final approval of manuscript: All authors. \\ \#These authors contributed equally to this work. \\ Correspondence to: Pyo Won Park, MD, PhD. Department of Thoracic and Cardiovascular Surgery, Samsung Medical Center, Sungkyunkwan \\ University School of Medicine, 81 Irwon-ro, Gangnam-gu, Seoul 06351, Korea. Email: pwpark@skku.edu.
}

Background: This study aimed to investigate the early and late outcomes of mechanical tricuspid valve replacement (mTVR).

Methods: We evaluated 113 patients ( 82 women; median age, 53 years) who underwent mTVR between 1995 and 2017. Based on a history of cardiac surgery, patients were divided into primary $(\mathrm{n}=42)$ and reoperative mTVR ( $n=71)$ groups. The median follow-up duration was 12.7 years in primary and 9.3 years in reoperative $\mathrm{mTVR}$, respectively $(\mathrm{P}=0.045)$.

Results: Patients in the reoperative group were older (54 vs. 46 years; $\mathrm{P}=0.007$ ) and showed higher central venous pressure $(16 \pm 6$ vs. $13 \pm 6 \mathrm{mmHg} ; \mathrm{P}=0.002)$ than the primary group. Early mortality occurred in 2 patients in the reoperative group ( 2 vs. $0 ; \mathrm{P}=0.529$ ). There was no significant difference in overall survival between the primary and reoperation groups (15-year survival rate: $86 \%$ vs. $78 \% ; \mathrm{P}=0.215)$. The independent risk factors of overall survival were age $[\mathrm{P}<0.001$; hazard ratio $(\mathrm{HR}), 1.11 ; 95 \%$ confidential interval (CI), 1.05-1.18], left ventricular ejection fraction of less than $40 \%$ ( $\mathrm{P}=0.001$; HR, 5.1; 95\% CI, 2.2128.2), and central venous pressure over $20 \mathrm{mmHg}(\mathrm{P}=0.016$; HR, 3.7; 95\% CI, 1.28-10.7). Overall survival did not differ between the age groups ( $<60$ vs. 60-70 years) in the reoperative group $(\mathrm{P}=0.772)$. Tricuspid valve thrombosis occurred in 8 patients ( 7 primary, 1 reoperative; $\mathrm{P}=0.004$ ).

Conclusions: The incidence of tricuspid valve thrombosis was significantly higher in the primary mTVR group compared with the reoperative mTVR group. The patients who underwent mTVR at a relatively young age showed good early and late outcomes in both groups.

Keywords: Prosthesis; tricuspid valve replacement (TVR); reoperation

Submitted Oct 06, 2020. Accepted for publication Jan 08, 2021.

doi: $10.21037 /$ jtd-20-3027

View this article at: http://dx.doi.org/10.21037/jtd-20-3027

^ ORCID: Byungjoon Park, 0000-0001-8746-3064; Dong Seop Jeong, 0000-0002-6947-8403; Wook Sung Kim, 0000-0001-7808-3385; Kiick Sung, 0000-0003-0768-9587; Pyo Won Park, 0000-0002-0892-4107. 


\section{Introduction}

Although tricuspid valve (TV) repair is the best option for surgical treatment for severe tricuspid regurgitation (TR), tricuspid valve replacement (TVR) is an inevitable procedure in patients with significant rheumatic changes, severe infective endocarditis, failed attempt of TV repair, and recurrent TR after previous TV annuloplasty. Current guidelines on valve selection for TV position recommend either biological or mechanical valve in patients between 60 and 70 years of age and mechanical prosthesis should be considered in patients already on anticoagulation because of a mechanical prosthesis in another valve position (IIa class) $(1,2)$.

However, many surgeons prefer biological prosthesis in this age group because of high rates of early mortality, limited life span, acceptable durability of biological valve, and high prevalence of valve thrombosis in mechanical TV. Currently, a biological valve is a more popular choice, even in patients younger than 60 years, because of the future possibility of transcatheter tricuspid valve-invalve implantation (TTVIVI) $(3,4)$. However, biological prosthesis are prone to structural and non-structural degeneration in the tricuspid position. Also, TTVIVI do not have late follow-up data on durability and other complications of the implanted valve.

Relatively young patients with mechanical prosthesis frequently presented with severe TR with mechanical valve problems in systemic circulation, such as subaortic pannus, mitral valve pannus, or mitral paravalvular leakage, at late follow-up period $(5,6)$. In our hospital, mechanical prosthesis became the preferred choice for TVR in patients with a mechanical valve in the left heart position.

However, mechanical TVR (mTVR) is associated with frequent valve thrombosis during the follow-up period. The choice between mechanical or biological prostheses in the tricuspid position is still controversial, especially in patients with mTVR after left side valve surgery. Therefore, patients who underwent mTVR in our institute were categorized into 2 groups, primary or reoperative mTVR, based on history of cardiac surgery. This study aimed to investigate the early and late clinical outcomes of mTVR between these 2 groups. We present the following article in accordance with the STROBE reporting checklist (available at http:// dx.doi.org/10.21037/jtd-20-3027).

\section{Methods}

\section{Study population}

Between January 1995 and December 2017, 113 consecutive patients (82 women) underwent mTVR at our hospital. During same study period, TV repair was performed in 1638 patients, and TVR with biological valve was performed in 67 patients. Patients younger than 18 years and patients who underwent repeat TVR were excluded. The median patient age was 53 years [interquartile range (IQR), 43-59 years]. The prevalence of atrial fibrillation was $78 \%$. The original valve disease was rheumatic in 85 patients $(75 \%)$, congenital in 11 patients $(10 \%)$ and infective endocarditis in 8 patients (7\%). Preoperative TR was severe in 95 patients (84\%). Based on history of cardiac surgery, patients were categorized into primary $(n=42)$ and reoperative mTVR $(n=71)$ groups. Previous cardiac surgery was performed in other hospitals in 57 patients $(80 \%)$. The study was conducted in accordance with the Declaration of Helsinki (as revised in 2013). The study protocol was approved by the hospital's Institutional Review Board (IRB no. 2018-07078). The requirement for patient consent was waived.

\section{Operative technique}

Our surgical technique and perioperative management of TV surgery were described previously $(7,8)$. Preoperative coagulation abnormalities resulting from oral anticoagulation therapy were completely reversed with infusion of vitamin $\mathrm{K}$ and fresh frozen plasma. Median sternotomy and bicaval cannulation were routinely used. If the right atrium was too dilated laterally, complete dissection of the right atrium and snaring of the inferior vena cava was a difficult and time consuming procedure. In this situation, a drainage sump catheter was inserted into the inferior vena cava. When left-side valve problems such as subaortic pannus, mitral pannus, and paravalvular leakage of the mitral valve were required surgical procedures, mTVR was performed after finishing the left-side valve surgery under cardioplegic arrest. Operative indication and technique of concomitant procedures were described in previously published reports (5-7). If the fixing sutures for implantation of TVR were difficult on the conduction area due to the friable thin septal leaflet of the TV or previous implantation of prosthetic aortic valve, a triangular shaped 

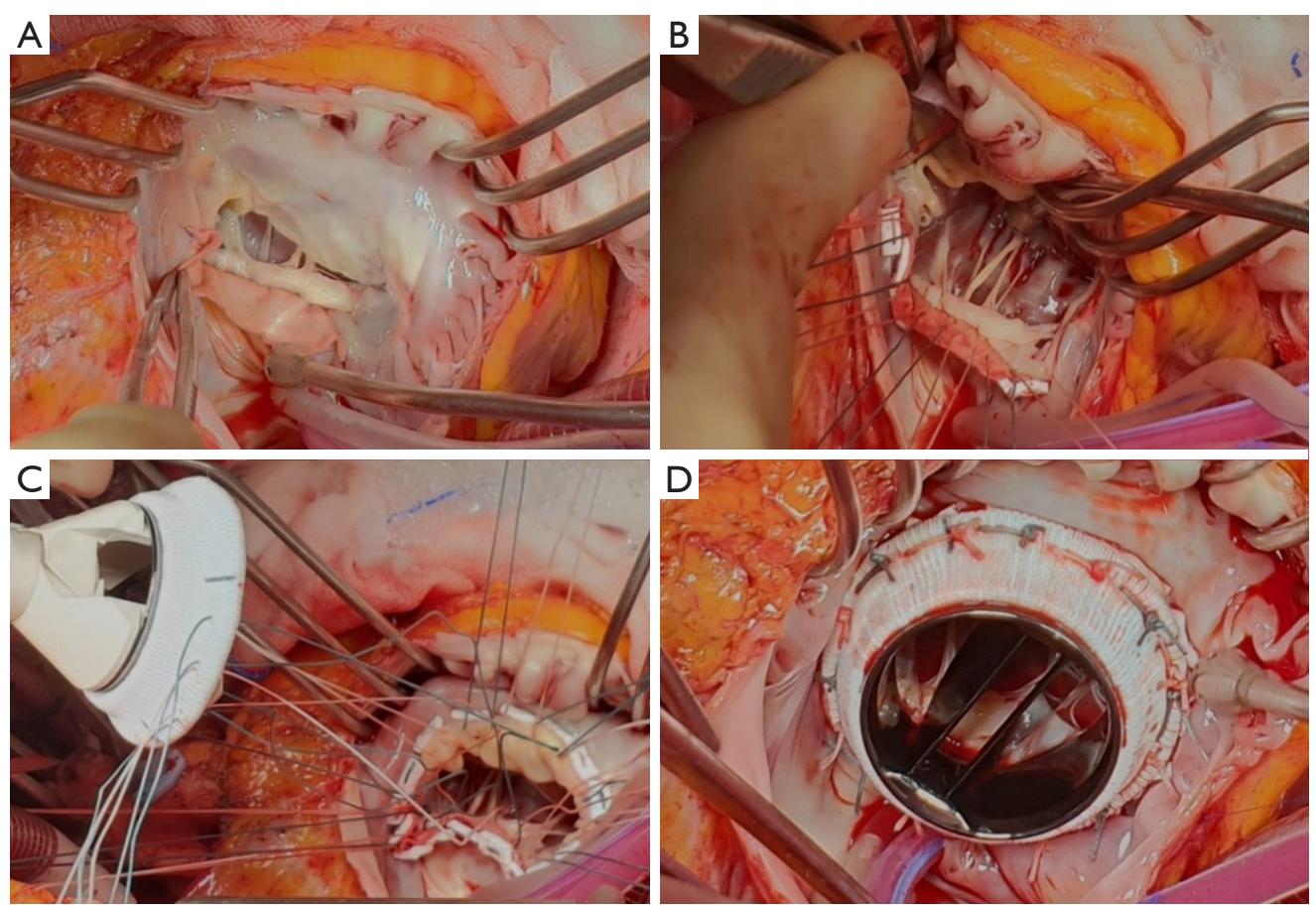

Figure 1 Surgical photograph of mechanical tricuspid valve replacement with pericardial reconstruction on the conduction area to prevent heart block. (A) A crescent-shaped bovine pericardial patch was applied to the thin septal and anterior leaflet on the conduction area. (B) Interrupted horizontal mattress stiches were made on the bovine pericardium. (C) Valve sutures were placed on an ON-X Confirm X valve. (D) Supra-annularly positioned Confirm-X valve was noted.

patch of bovine pericardial was applied to the conduction area with 6-0 polypropylene running sutures to provide secure valve sutures and to prevent heart block and paravalvular leakage (Figure 1).

Modified ultrafiltration was used in all patients. If the contractile function of the right ventricle did not return to near normal or the target CVP of $12 \mathrm{mmHg}$ was not obtained with filtration, modified ultrafiltration after transfusion of packed red blood cell and fresh frozen plasma were continued before increasing doses of inotropic supports to reduce pulmonary resistance, which is crucial for a smooth postoperative hospital course after TVR. Oral sildenafil (10-20 mg/3-4 times a day) was added as soon as possible after transfer to the intensive care unit (ICU) since 2000.

\section{Statistics}

Data were statistically analyzed using STATA version 16 (StataCorp LLC, College Station, TX, USA). Distribution of general characteristics, preoperative laboratory data, echocardiographic data, and operative data were analyzed using means with standard deviation for normally distributed continuous data. Medians with IQR were used for other continuous variables. Student's paired $t$-test was used to compare continuous variables. Kaplan-Meier and Cox hazard modeling was calculated for overall and eventfree survival rates. Analyzed predictors and risk factors were regarded as significant in accordance with the ratio formula with $\mathrm{P}$ values less than 0.05 .

\section{Follow-up}

Early mortality was defined as death during hospitalization or within 30 days after the operation. Cause of death was classified as cardiac-related (sudden death, anticoagulationrelated neurological complications, heart failure, or myocardial infarction) or non-cardiac death. The incidence of tricuspid valve thrombosis was calculated, excluding the time interval after heart transplantation, in the followup period. Other definitions of morbidity and mortality followed the 'Guidelines for reporting mortality and morbidity after cardiac valve interventions' (9). Followup survival data were available for all patients. Data for $87 \%$ of patients followed by our hospital were acquired by 
reviewing medical records. Data for $6 \%$ of patients followed by other hospitals were collected by direct telephone interviews with patients or their families. The remaining $7 \%$ of patients were lost to follow-up, but we confirmed their survival using Korea National Medical Insurance information. Follow-up echocardiography at our hospital was available in $90 \%$ of patients at 1 year, $73 \%$ of patients at 3 years, $59 \%$ of patients at 5 years, and $56 \%$ of patients at 7 years. The median follow-up duration was 153 months (IQR, 56-181 month) in the primary group and 112 months (IQR, 48-156 month) in the reoperative mTVR group $(\mathrm{P}=0.045)$.

\section{Results}

\section{Patient characteristics}

Patients in the reoperative mTVR group were older (median age, 54 y vs. $46 \mathrm{y} ; \mathrm{P}=0.007)$ and had a higher logistic Euroscore $(10.9 \pm 12.5$ vs. $3.5 \pm 3.7 ; \mathrm{P}<0.001)$. Twelve patients (17\%) had a history of 2 cardiac procedures, and 2 patients (3\%) had previously undergone 3 procedures. The time interval from last cardiac surgery was $13.9 \pm 7.2$ years in the reoperative group. The status of left-side valve surgery for the reoperative group was double valve replacement in 33 patients (46\%), mitral valve replacement in 25 patients (35\%), mitral valve repair or open mitral commissurotomy in 5 patients (7\%), and TV repair in 3 patients (5\%). A mechanical valve had been implanted in 56 patients $(79 \%)$ in the reoperative mTVR group. The preoperative platelet count was lower in the reoperative group, but did not reach statistical significance when compared with the primary group $(\mathrm{P}=0.119)$. Preoperative characteristics of patients in each group are described in Table 1.

\section{Operative data}

The mean CVP in the operating room for the reoperative mTVR group was significantly higher than that for the primary mTVR group $(16.3 \pm 6.2$ vs. $12.5 \pm 5.9 \mathrm{mmHg}$; $\mathrm{P}=0.002$. Thirty-two patients $(45 \%)$ in the reoperative mTVR group had a history of tricuspid annuloplasty. Isolated mTVR was performed in 23 patients (20\%). The tricuspid valve pathology and concomitant procedures in each group were described in Table 2. The implanted mechanical valve for TVR was St. Jude Medical in 57 patients [50\%; $27 \mathrm{~mm}(\mathrm{n}=5), 29 \mathrm{~mm}(\mathrm{n}=11), 31 \mathrm{~mm}(\mathrm{n}=24)$, $33 \mathrm{~mm}(\mathrm{n}=17)], \mathrm{ON}-\mathrm{X}$ in 40 patients [35\%; $25 \mathrm{~mm}(\mathrm{n}=11)$,
$27-29 \mathrm{~mm}(\mathrm{n}=16), 31-33 \mathrm{~mm}(\mathrm{n}=9), 25-33 \mathrm{~mm}(\mathrm{n}=4)]$, ATS in 12 patients $[11 \% ; 29 \mathrm{~mm}(\mathrm{n}=3), 31 \mathrm{~mm}(\mathrm{n}=3), 33 \mathrm{~mm}$ $(\mathrm{n}=3))$, and Sorin in 4 patients $(4 \% ; 29 \mathrm{~mm}(\mathrm{n}=2), 31 \mathrm{~mm}$ $(\mathrm{n}=2)]$. The total amount of ultrafiltration during operation was $61 \pm 32 \mathrm{ml} / \mathrm{kg}$ in the primary $\mathrm{mTVR}$ group and $101 \pm 41 \mathrm{ml} / \mathrm{kg}$ in the reoperative $\mathrm{mTVR}$ group $(\mathrm{P}<0.001)$.

\section{Early outcomes}

The mean of preoperative CVP was decreased from $12.5 \pm 5.9$ to $8.7 \pm 3.1 \mathrm{mmHg}(\mathrm{P}<0.001)$ and from $16.3 \pm 4.4$ to $9.5 \pm 4.3 \mathrm{mmHg}(\mathrm{P}<0.001) 2$ hours after arrival to intensive care unit in the primary and reoperative groups, respectively. The primary mTVR group had no early mortality, heart block, or reoperation for bleeding. In the reoperative group, there were 2 hospital deaths in patients with emergent mTVR for prosthetic valve endocarditis in left heart position. Other early complications are described in Table 3. The ventilator time, length of intensive care unit stay, and length of hospital stay did not differ between the 2 groups.

\section{Late outcomes}

The average mean INR was $2.39 \pm 0.23$ and $2.32 \pm 0.28$ in primary $\mathrm{mTVR}$ and reoperative $\mathrm{mTVR}$, respectively $(\mathrm{P}=0.207)$. Eight patients had tricuspid valve thrombosis ( 7 in the primary group and 1 in the reoperative group; $\mathrm{P}=0.004)$. All 8 patients were treated with urokinase infusion. In 7 patients, the TV malfunctions owing to thrombosis were recovered to normal leaflet motion with thrombolytic therapy. One patient who had partial response to thrombolytic therapy eventually underwent repeat TVR due to malfunction of TV 2 years after the TV thrombosis event. Four patients underwent repeat TVR owing to endocarditis $(n=1)$, paravalvular leakage $(n=1)$, valve malfunction by pannus $(n=1)$, and thrombosis $(n=1)$. Another 4 patients underwent heart transplantation (30, 101, 156, and 189 months after mTVR) and survived. The indications of heart transplantation were $\mathrm{LV}$ dysfunction and mitral paravalvular leakage $(\mathrm{n}=2)$, ECMO weaning failure after repeated AVR for severe subaortic pannus $(n=1)$, and $\mathrm{LV}$ and $\mathrm{RV}$ dysfunction $(\mathrm{n}=1)$. The transtricuspid mean pressure gradient of mechanical TV was $2.41 \pm 1.01 \mathrm{mmHg}$ $(\mathrm{n}=98), 2.46 \pm 1.21 \mathrm{mmHg}(\mathrm{n}=94), 2.48 \pm 1.30 \mathrm{mmHg}(\mathrm{n}=47)$ at discharge, 1 year, and 7 years after surgery, respectively.

Overall survival did not differ between the groups $(\mathrm{P}=0.215)$ (Figure 2). The 15-year survival rates, including 
Table 1 Patient's preoperative characteristics

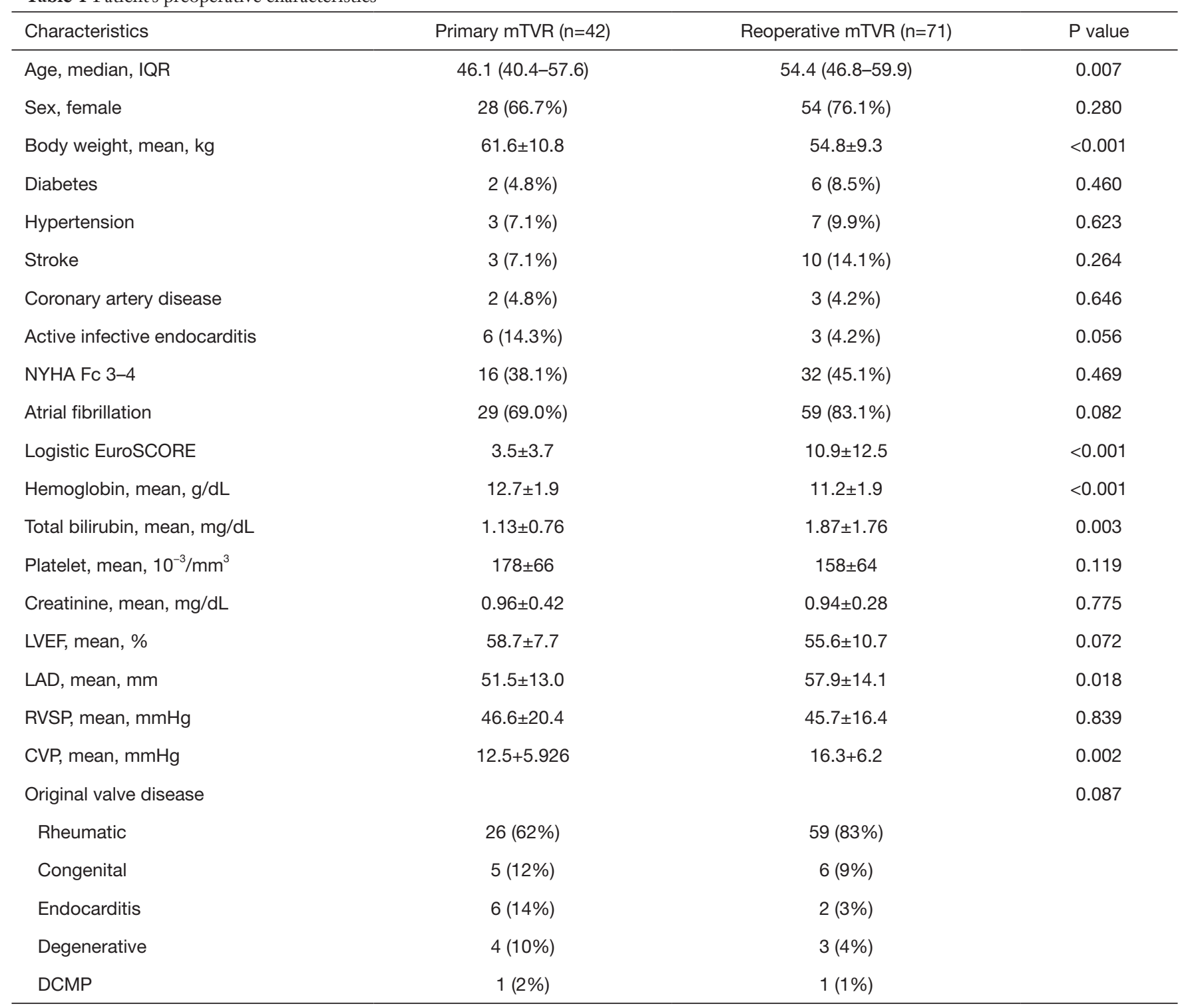

mTVR, mechanical tricuspid valve replacement; IQR, interquartile range; NYHA fc, New York Heart Association functional classification; LVEF, left ventricular ejection fraction; LAD, left atrium diameter; RVSP, right ventricular systolic pressure; CVP, central venous pressure.

operative mortality, were $86 \%$ and $78 \%$ in the primary and reoperative mTVR groups, respectively. The independent risk factors of overall survival were age $[\mathrm{P}<0.001$; hazard ratio (HR), 1.11; 95\% confidential interval (CI), 1.05-1.18], left ventricular ejection fraction of less than $40 \%(\mathrm{P}=0.001$; HR, 5.1; 95\% CI, 2.21-28.2), and CVP of greater than $20 \mathrm{mmHg}(\mathrm{P}=0.016$; HR, 3.7; 95\% CI, 1.28-10.7). Reoperative mTVR was not a risk factor for overall survival $(\mathrm{P}=0.223)$. Overall survival did not differ between patients aged younger than 60 years (54 patients) and those aged 60 to 70 years (17 patients) in the reoperative group $(\mathrm{P}=0.772)$ (Figure 3).

\section{Discussion}

The present study had 4 main findings. First, the early and late outcomes in relatively young patients with mechanical TVR were reasonably good in both the primary and reoperative mTVR groups. Second, reoperative mTVR was not a risk factor for early mortality and overall survival. 
Table 2 Operative data

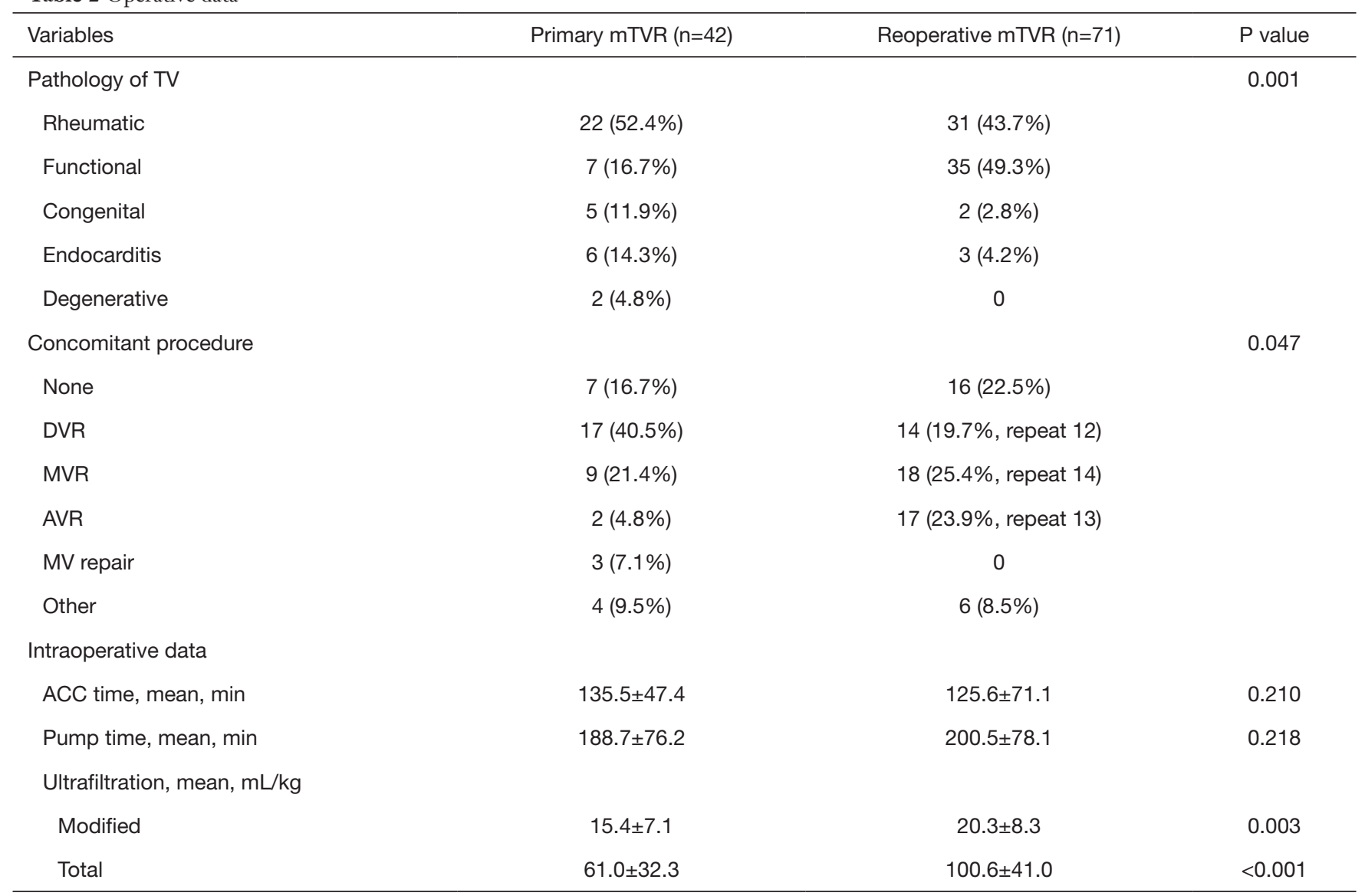

mTVR, mechanical tricuspid valve replacement; TV, tricuspid valve; DVR, double valve replacement; MVR, mitral valve replacement; AVR, aortic valve replacement; ACC, aortic cross clamp.

Third, the prevalence of valve thrombosis of mTVR was significantly higher in the primary mTVR group than in the reoperative mTVR group. TV thrombosis is rarely fatal in bileaflet mechanical valve and responded well to thrombolytic therapy. Finally, overall survival did not differ between patients aged younger than 60 years and those aged 60 to 70 years in the reoperative group.

The most reported studies have revealed that the type of implanted prosthesis in the tricuspid position does not affect early and long-term outcomes $(10,11)$. However, some reports have recommended biological prosthesis because of acceptable durability $(12,13)$ or mechanical prosthesis of new bileaflet valve due to excellent hemodynamic function and low incidence of late reoperation $(14,15)$. The main disadvantages of biological prostheses are limited durability, high incidence of using anticoagulation therapy for concomitant disease, and unacceptable late hemodynamic function. The disadvantages of mechanical prostheses are a high incidence of bleeding complications and tricuspid valve thrombosis.

In this series, the incidence of tricuspid valve thrombosis, which is a main drawback of mTVR, was significantly higher in the primary mTVR group compared with the reoperative mTVR group $(\mathrm{P}=0.004)$. One possible explanation of this finding may be attributed to preexisting decreased platelet count and impaired platelet function in the reoperative group and possible higher target international normalized ratio due to the higher incidence of atrial fibrillation in the reoperative group. A higher target international normalized ratio or adding aspirin up to 10 years after mTVR may be considered in patients with primary mTVR to prevent TV thrombosis. Further study is required to prevent TV thrombosis in patients with a normal platelet count and sinus rhythm in the primary mTVR group.

Another advantage of mTVR is excellent hemodynamic function at late follow-up. In our series, the tricuspid 
Table 3 Early and late outcomes

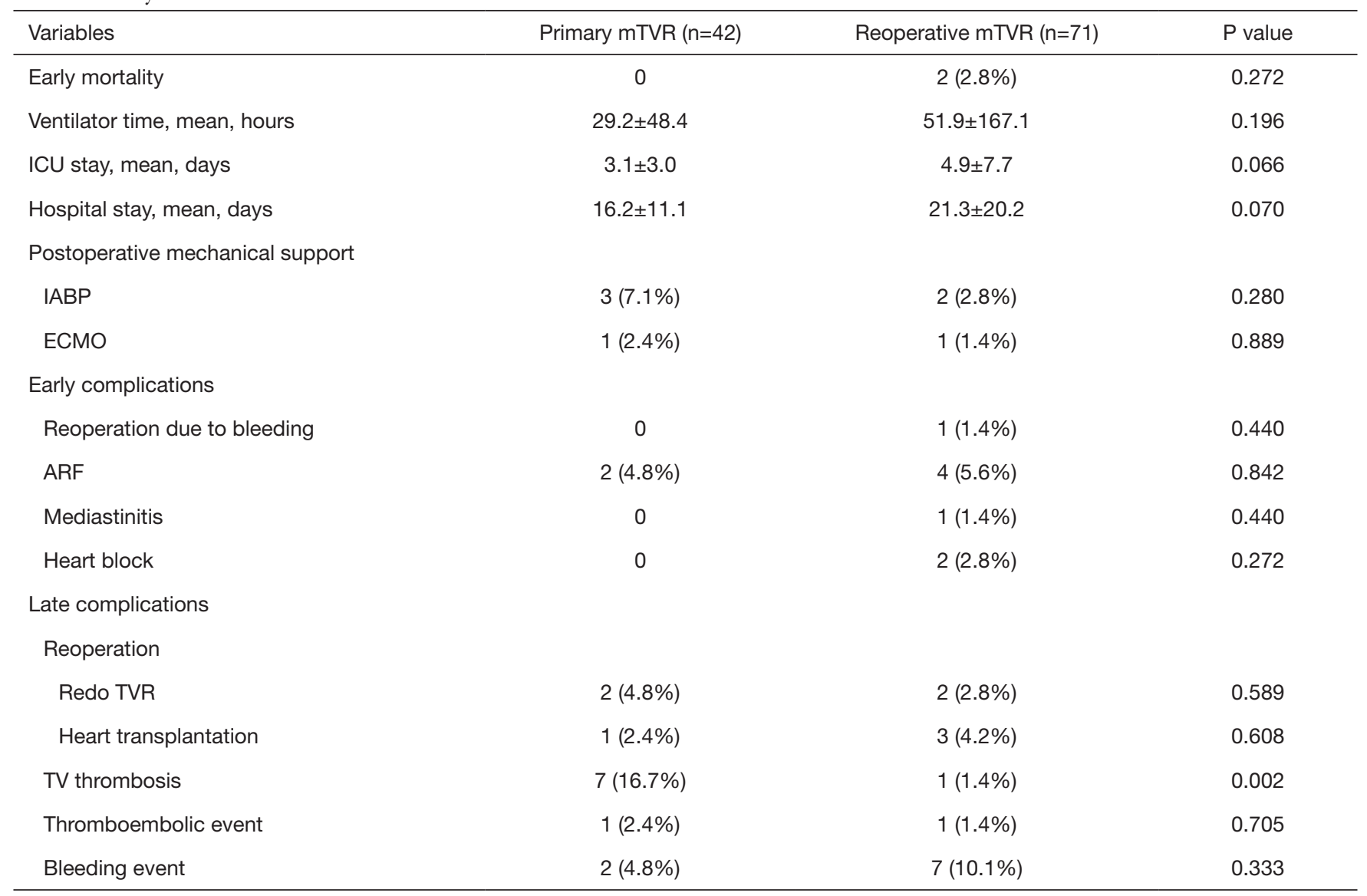

mTVR, mechanical tricuspid valve replacement; IABP, intra-aortic balloon pumping; ECMO, extracorporeal membrane oxygenator; ARF, acute renal failure.

transprosthetic mean pressure gradients were well maintained up to 7 years after surgery. Nagano et al. (16) reported that echocardiographic examination in patients who underwent biological TVR with Carpentier-Edwards pericardial xenograft revealed subclinical prosthetic dysfunction in $35 \%$ of patients who were followed for longer than 5 years. Dearani at Mayo clinic recommended porcine bio-prosthesis which is thin and pliable compared with bovine bio-prosthesis when performing TVR. He explained this choice by writing that the relatively thicker and stiffer pericardial leaflets do not open and close properly with the low opening (right atrial) and low closing (right ventricular) pressures often combined with depressed RV failure (17).

The advantage of biological TVR is future application of TTVIVI. TTVIVI is an emerging treatment for patients with structural degeneration of a biological tricuspid valve, which carries a high rate of early mortality. Although the early procedural success rate was excellent, there are still concerns on repeat TTVIVI and surgical TVR for thrombosis, endocarditis, and recurrent TR or tricuspid stenosis. However, TTVIVI is a useful and durable intervention in many cases. Further studies are necessary to determine long-term valve function and to define risk factors for poor outcome.

In our series, reoperative mTVR and prolonged aortic cross time were not risk factors for early mortality. The reasons for the low early mortality rate in our study may be associated with relatively young age, no significant coronary artery disease, low incidence of New York Heart Association class IV, no prolonged trial of TV repair, low threshold for TVR in patients with repeated cardiac surgery, mostly a single surgeon's experience, and improved perioperative management, including modified ultrafiltration to reduce afterload of right ventricle.

Placement of valve sutures on the conduction area 
A

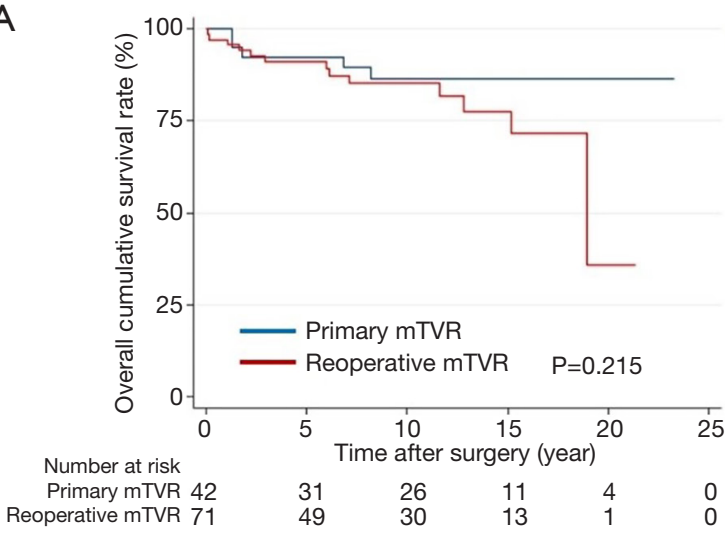

C

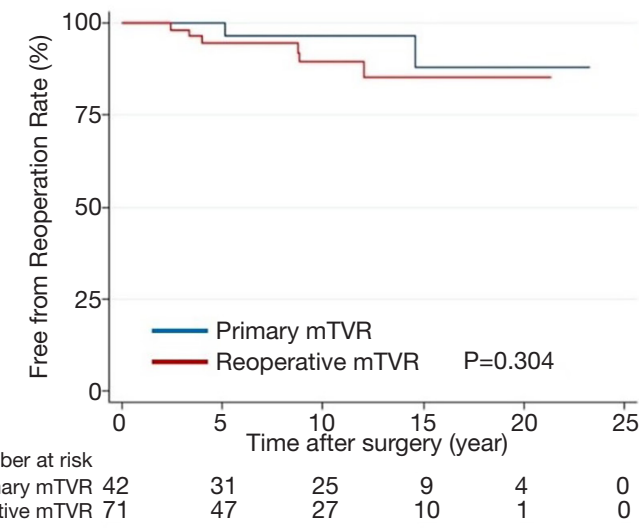

B

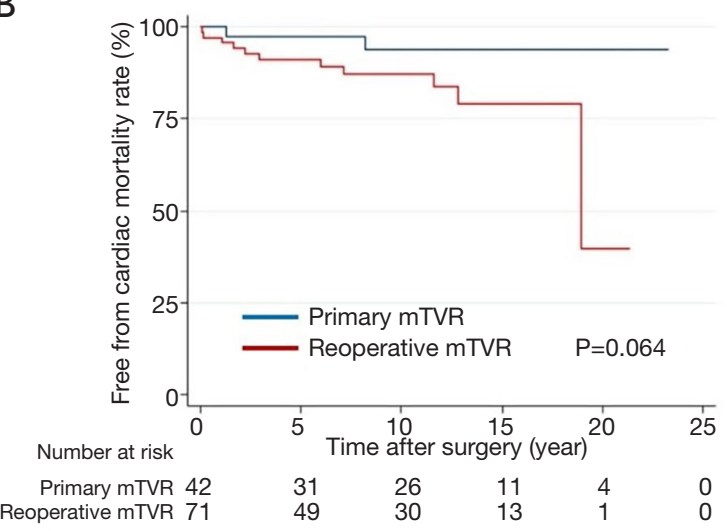

D

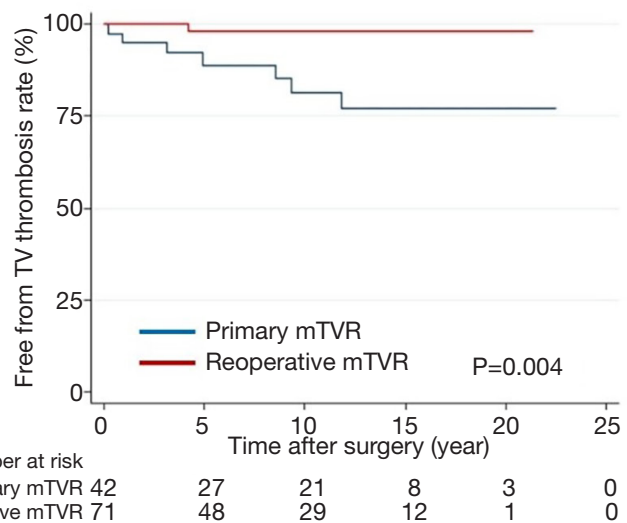

Figure 2 Kaplan-Meier curve for (A) overall survival, (B) freedom from cardiac related mortality, (C) freedom from reoperation, and (D) freedom from tricuspid valve thrombosis.

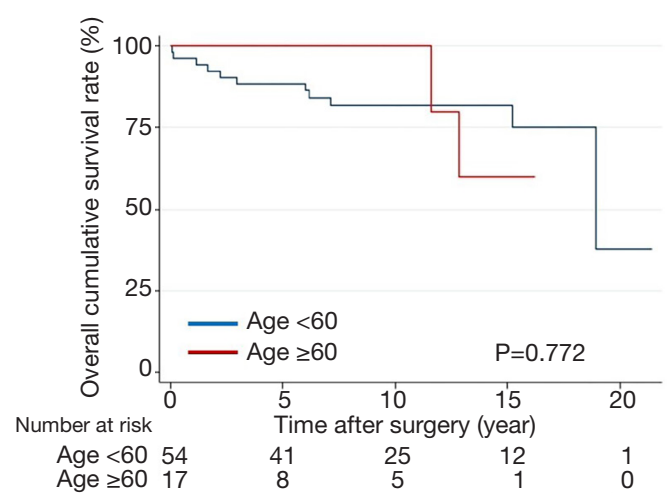

Figure 3 Kaplan-Meier curve for overall survival between patients aged older than 60 years and those aged younger than 60 years in the reoperative mechanical tricuspid valve replacement group.

for TVR is technically difficult in patients with aortic valve replacement or double valve replacement owing to the protruding aortic prosthesis. To prevent complete heart block and apply secure fixation of pledged sutures, triangular shaped bovine pericardium was applied on the conduction area. This technique may also prevent interference of subvalvular apparatus with mechanical bileaflet valve and leaflet adhesion to biological prosthesis.

Another important point is the perioperative management of anticoagulation therapy in mTVR to prevent postoperative bleeding and reoperation, hematoma formation in the pericardial space, and early thrombosis in the right atrium and mechanical tricuspid valve. Complete reversal of preoperative effect of oral anticoagulation therapy with infusion of vitamin $\mathrm{K}$ and fresh frozen plasma, timely infusion of blood products (fresh frozen plasma, platelets concentration, cryoprecipitate) in the operating room, precise bleeding control, early start of small dose of intravenous heparin after the stop of bleeding and close monitoring of platelet count, international normalized ratio, and activated prothrombin time in the intensive care unit. Postoperative hematoma formation in the pericardial 
space seem to induce further impairment of RV function and increase the risk of renal dysfunction.

In this study, the 15 -year survival rates were $86 \%$ and $78 \%$ in the primary and reoperative groups, respectively. The reason for good late survival of mTVR may be attributed to younger age, early referral of patients with severe TR, aggressive concomitant surgery for left side valve problem, timely thrombolytic therapy for valve thrombosis, application of heart transplantation, and a close followup program. There is nothing to extend the durability of biological valve after surgery. However, anticoagulationrelated complications of mechanical TVR may be reduced by a patient's education and easy access to the surgeon or cardiologist at the time of anticoagulation-related events.

Interestingly, overall survival did not differ between selected patients aged 60 and 70 years (18 patients) and those aged younger than 60 years (53 patients) in the reoperative mTVR group $(\mathrm{P}=0.772)$. Therefore, we believe that mechanical valve for tricuspid position is a reasonable choice in selected patients who have left side mechanical prosthesis and are younger than 70 years old without significant coronary disease, New York Heart Association class IV, left ventricular ejection fraction less than $40 \%$, and preoperative CVP greater than $20 \mathrm{mmHg}$.

The present study had several limitations. First, baseline patient characteristics were different between the primary mTVR and reoperative mTVR groups. A propensity matching study was not applied due to the small number of enrolled patients in each group and the different surgical approach in concomitant procedures. Second, we did not include preoperative parameters that represent $\mathrm{RV}$ function due to incomplete data. Therefore, we used initial CVP data in the operating room after anesthetic induction and noted that CVP greater than $20 \mathrm{mmHg}$ was an independent risk factor for late survival. Lastly, most patients (75\%) underwent mTVR by a single surgeon (Pyo Won Park) and patients were closely followed-up through the outpatient clinic of the surgical department, which is important for maintaining the optimal condition of oral anticoagulation therapy. In our series, a high incidence of rheumatic heart disease $(75 \%)$ and concomitant procedures $(80 \%)$ were observed: these different disease patterns and treatment strategies may not be generalized to western countries.

\section{Conclusions}

In conclusion, the incidence of tricuspid valve thrombosis was significantly higher in the primary mTVR group compared with the reoperative mTVR group $(\mathrm{P}=0.004)$. The patients who underwent mTVR at a relatively young age showed good early and late outcomes in both groups.

\section{Acknowledgments}

Funding: None.

\section{Footnote}

Reporting Checklist: The authors have completed the STROBE reporting checklist. Available at http://dx.doi. org/10.21037/jtd-20-3027

Data Sharing Statement: Available at http://dx.doi. org/10.21037/jtd-20-3027

Conflicts of Interest: All authors have completed the ICMJE uniform disclosure form (available at http://dx.doi. org/10.21037/jtd-20-3027). The authors have no conflicts of interest to declare.

Etbical Statement: The authors are accountable for all aspects of the work in ensuring that questions related to the accuracy or integrity of any part of the work are appropriately investigated and resolved. The study was conducted in accordance with the Declaration of Helsinki (as revised in 2013). The study protocol was approved by the hospital's Institutional Review Board (IRB no. 2018-07078). The requirement for patient consent was waived.

Open Access Statement: This is an Open Access article distributed in accordance with the Creative Commons Attribution-NonCommercial-NoDerivs 4.0 International License (CC BY-NC-ND 4.0), which permits the noncommercial replication and distribution of the article with the strict proviso that no changes or edits are made and the original work is properly cited (including links to both the formal publication through the relevant DOI and the license). See: https://creativecommons.org/licenses/by-nc-nd/4.0/.

\section{References}

1. Baumgartner H, Falk V, Bax JJ, et al. 2017 ESC/EACTS guidelines for the management of valvular heart disease. Eur Heart J 2017;38:2739-91.

2. Nishimura RA, Otto CM, Bonow RO, et al. 2014 AHA/ ACC guideline for the management of patients with 
valvular heart disease. Circulation 2014;129:2440-92.

3. Taggart NW, Cabalka AK, Eicken A, et al. Outcomes of transcatheter tricuspid valve-in-valve implantation in patients with Ebstein anomaly. Am J Cardiol 2018;121:262-8.

4. McElhinney DB, Aboulhosn JA, Dvir D, et al. Mid-term valve-related outcomes after transcatheter tricuspid valvein-valve or valve-in-ring replacement. J Am Coll Cardiol 2019;73:148-57.

5. Jeong DS, Park PW, Mwambu TP, et al. Tricuspid reoperation after left-sided Rheumatic Valve Operations. Ann Thorac Surg 2013;95:2007-13.

6. Park PW, Park B, Jeong DS, et al. Clinical outcomes of repeat aortic valve replacement for subaortic pannus in mechanical aortic valve. Circ J 2018;82:2535-41.

7. Park CK, Park PW, Sung K, et al. Early and midterm outcomes for tricuspid valve surgery after left-sided valve surgery. Ann Thorac Surg 2009;88:1216-23.

8. Chang HW, Jeong DS, Cho YH, et al. Tricuspid valve replacement vs. repair in severe tricuspid regurgitation. Circ J 2017;81:330-8.

9. Akins CW, Miller DC, Turina MI, et al. Guidelines for reporting mortality and morbidity after cardiac valve interventions. Ann Thorac Surg 2008;85:1490-5.

10. Rizzoli G, Vendramin I, Nesseris G, et al. Biological or mechanical prostheses in tricuspid position? A meta-

Cite this article as: Park B, Jeong DS, Kim WS, Sung K, Park PW. Reappraisal of mechanical tricuspid valve replacement in the current era: a single center retrospective study. J Thorac Dis 2021;13(6):3359-3368. doi: 10.21037/jtd-20-3027 analysis of intra-institutional results. Ann Thorac Surg 2004;77:1607-14.

11. Garatti A, Nano G, Bruschi G, et al. Twenty-five Year outcomes of tricuspid valve replacement comparing mechanical and biologic prostheses. Ann Thorac Surg 2012;93:1146-53.

12. Carrier M, Hébert Y, Pellerin M, et al. Tricuspid valve replacement: An analysis of 25 years of experience at a single center. Ann Thorac Surg 2003;75:47-50.

13. Anselmi A, Ruggieri VG, Harmouche M, et al. Appraisal of long-term outcomes of tricuspid valve replacement in the current perspective. Ann Thorac Surg 2016;101:863-71.

14. Nakano K, Koyanagi H, Hashimoto A, et al. Tricuspid valve replacement with bileaflet St. Jude Medical valve prosthesis. J Thorac Cardiovasc Surg 1994;108:888-92.

15. Kaplan M, Kut MS, Demirtas MM, et al. Prosthetic replacement of tricuspid valve: bioprosthetic or mechanical. Ann Thorac Surg 2002;73:467-73.

16. Nakano K, Eishi K, Kosakai Y, et al. Ten-year experience with the Carpentier-Edwards pericardial xenograft in the tricuspid position. J Thorac Cardiovasc Surg 1996;111:605-12.

17. Dearani JA. Editorial comment: Lessons learned with tricuspid valve replacement. Eur J Cardiothorac Surg 2014;45:90-1. 